\title{
GROWTH OF CZECH BREASTFED CHILDREN IN THE FIRST YEAR OF THEIR LIFE: A COMPARISON WITH NEW WHO GROWTH STANDARDS AND ACTUAL CZECH REFERENCE DATA
}

\author{
M. Paulová ${ }^{1}$, J. Vignerová ${ }^{1}$ J. Riedlová ${ }^{2}$, D. Schneidrová ${ }^{3}$ \\ ${ }^{I}$ Dept. of Health Promotion and Child and Adolescent Health, National Institute of Public Health, ${ }^{2}$ Dept. of \\ Anatomy, ${ }^{3}$ Dept. of Child and Youth Health, 3rd Faculty of Medicine, Charles University, Prague, Czech \\ Republic
}

Background and aims: The growth pattern of a breastfed child is specific and exclusive breastfeeding might be prematurely finished if inadequate growth charts are used.

In 2006, WHO published new growth standards for children aged 0-5 years based on growth data of breastfed children. In 2008, the similar study on the growth of Czech breastfed children was started. Our aim was to compare the growth of Czech breastfed children with new WHO growth standards as well as with actual Czech reference data (collected regardless of children's mode of feeding).

Methods: Data on growth and socio-economic status of nearly 1700 Czech children breastfed for at least 4 months were collected. The data on length-for-age, weight-for-age and weight-for-length were compared with WHO standards and Czech references.

\section{Results:}

1) Czech breastfed children are longer than children from the WHO study. Their height-for-age values don't differ significantly from the Czech reference data.

2) Weight-for-age values of Czech breastfed children in the first months are lower compared to the WHO standards and higher compared to the Czech reference data.

3) Weight-for-length values of Czech breastfed children don't differ markedly compared to the Czech reference data.

Conclusions: Implementation of the new WHO standards in the Czech Republic might influence the assessment of infant feeding on adequacy. Presented results will provide data for methodological instructions on the assessment of growth of Czech breastfed children. The purpose is to support sustained breastfeeding.

Research is supported by the grant of the IGA MoH CR, No. NS 99744/2008. 